1 Serviço de Saúde Dr. Cândido Ferreira (SSCF) Campinas (SP), Brasil. dvdob@yahoo.com.br

\title{
A resistência como analisador da saúde mental em Campinas (SP): contribuições da Análise Institucional
}

\author{
Resistance as mental health analyzer in Campinas (SP): contributions \\ of Institutional Analysis
}

Daniel Vannucci Dobies', Solange L'Abbate ${ }^{\mathbf{2}}$

\begin{abstract}
RESUMO O artigo analisa um movimento de resistência de um Fórum Colegiado de Saúde Mental em Campinas (SP), cuja atual conjuntura coloca em risco o seu histórico inovador e o cuidado em rede na área de saúde mental devido ao enrijecimento organizacional e à tensão entre o atual governo municipal e a entidade parceira nessa área. Foram feitas observações, entrevistas e adotada a Análise Institucional como referencial teórico-metodológico. Concluiu-se que os movimentos de resistência são de grande relevância para os profissionais dessa rede, e sua análise é fundamental para a qualificação do cuidado compartilhado, possibilitando um enfrentamento mais efetivo às adversidades conjunturais.
\end{abstract}

PALAVRAS-CHAVE Saúde mental. Rede social. Ciências sociais. Fóruns de discussão. Equipe de assistência ao paciente.

\begin{abstract}
The article analyzes a resistance movement of a Collegiate Forum of Mental Health in Campinas (SP), whose current situation endangers its innovative history and networked care in the mental health area, due to organizational rigidity and tension between the current municipal government and the partner organization in this area. They were made observations, interviews and Institutional Analysis was adopted as theoretical and methodological framework. It concludes that resistance movements are of great importance for the professionals of that network, and its analysis is fundamental to the qualification of shared care, enabling a more effective confrontation to the conjunctural adversity.
\end{abstract}

KEYWORDS Mental health. Social networking. Social sciences. Discussion forums. Patient care team. 


\section{Da inovação ao enquadre: uma breve descrição da trajetória da saúde mental em Campinas (SP)}

\section{A cidade de Campinas (SP) tem um histórico} de pioneirismo na implantação de serviços e práticas de cuidado na área da saúde mental. No final da década de 1970, o município já contava com um ambulatório de saúde mental que mantinha aproximações com as unidades básicas, devido, sobretudo, à força de movimentos sociais que lutaram pela atenção pública à saúde e ao fato de muitas reivindicações desses movimentos terem sido contempladas por diretrizes da política municipal de saúde. Nos anos 1980, recebeu um ambulatório de saúde mental estadual, e foram criadas enfermarias e serviços de urgência pelas universidades do município (CAMPOS, 2000; L'ABBATE, 2010).

O município também foi um dos pioneiros na implantação de Centros de Atenção Psicossocial (Caps) e de uma rede de serviços substitutivos, incluindo centros de convivência, oficinas de trabalho, serviços de urgência psiquiátrica e serviços de residência terapêutica (FIGUEIREDO; SANTOS, 2008). Esse processo relaciona-se à Reforma Psiquiátrica Brasileira que teve início mais concretamente no final da década de 1970, na conjuntura da redemocratização, fundada na crítica ao sistema da saúde mental do nosso País, ao saber psiquiátrico e às instituições da psiquiátrica clássica (AMARANTE, 1995).

Um marco importante desse processo em Campinas ocorreu durante a década de 1990, quando a Prefeitura Municipal estabeleceu uma parceria de cogestão com o Sanatório Dr. Cândido Ferreira - fundado no início do século XX. A partir disso, este passou a integrar a rede municipal de saúde. Entretanto, a expansão dos serviços substitutivos ocorreu mais intensamente a partir de 2001, com o incremento da parceria com o renomeado Serviço de Saúde Dr. Cândido
Ferreira (SSCF), no processo da implantação do Projeto Paideia de Saúde da Família, que propunha novas concepções e arranjos organizacionais para a rede de saúde do município. Naquele momento, as equipes de saúde mental, presentes na Atenção Básica (AB), passaram a oferecer apoio matricial ${ }^{1}$ às equipes de referência (médicos, enfermeiros, técnicos de enfermagem, agentes comunitários etc.) (FIGUEIREDO; SANTOS, 2008).

Grande parte desses serviços, assim como alguns arranjos, foram criados e financiados com recursos do município para lidar com as necessidades identificadas, sem estar atrelado à disponibilização de recursos específicos do governo federal. Algumas dessas inovações locais posteriormente foram incorporadas em políticas públicas nacionais, como os serviços residenciais terapêuticos e o apoio matricial.

Entre o final de 2011 e o início de 2012, foi deflagrada uma importante crise na saúde mental relacionada aos convênios da Prefeitura Municipal com o SSCF, especialmente um deles, denominado PSF, em referência ao Programa Saúde da Família. À época, havia dois convênios: Saúde Mental e PSF. O primeiro correspondia exclusivamente à área da saúde mental enquanto o segundo referia-se aos profissionais contratados para a área da saúde em geral, incluindo $A B$, hospitais e serviços de urgência. $O$ principal aspecto de irregularidade apontado pelas instâncias do judiciário era de que os trabalhadores não poderiam ser contratados por uma organização (SSCF) e estarem sob gestão de outra (Prefeitura), como era o caso dos profissionais contratados via Convênio PSF.

No convênio a ser extinto, estavam incluídos alguns apoiadores institucionais de saúde mental e muitos profissionais da área de saúde mental que atuavam na AB. O encerramento do convênio foi anunciado em janeiro de 2012, mas sofreu prorrogações para que a transição provocasse menos desassistência, de modo que os 1.308 funcionários fossem

\footnotetext{
1 “O Apoio Matricial em saúde objetiva assegurar retaguarda especializada a equipes e profissionais encarregados da atenção a problemas de saúde, de maneira personalizada e interativa. Opera com o conceito de núcleo e de campo. Assim: um especialista com determinado núcleo, apoia especialistas com outro núcleo de formação, objetivando a ampliação da eficácia de sua atuação. Trata-se de uma metodologia de trabalho complementar àquela prevista em sistemas hierarquizados, a saber: mecanismos de referência e contrarreferência, protocolos e centros de regulação. O Apoio Matricial pretende oferecer tanto retaguarda assistencial quanto suporte técnico-pedagógico às equipes de referência" (CUNHA; CAMPOS, 2011, P. 964).
} 
demitidos mediante reposição de vagas via concurso público. Houve várias discussões em espaços colegiados e de controle social para que, além do número de trabalhadores, fosse mantido um modelo de atenção à saúde mental coerente com a Reforma Psiquiátrica.

No decorrer dessa crise, que resultou no encerramento do Convênio PSF, também ocorreram mudanças no Convênio de Saúde Mental, pois incorporou todos os Caps e outros equipamentos de saúde mental, além de, temporariamente, manter os profissionais de saúde mental alocados na $\mathrm{AB}$ até a conclusão das reposições via concurso público.

O governo municipal eleito em 2013 não reconheceu a lei de cogestão, que mantinha uma relação mais estreita entre SSCF e a Prefeitura, fazendo emergir questionamentos relacionados com a ocupação de prédios públicos pelos serviços gerenciados pelo SSCF e a cessão de profissionais concursados para serviços gerenciados pelo SSCF. Além desse movimento para separar as duas organizações, passa a haver questionamentos a respeito do número de trabalhadores por serviço, tomando como parâmetro as diretrizes gerais do Ministério da Saúde, sem considerar os aspectos peculiares de cada serviço. É dado início ao processo de enxugamento das equipes, com a não reposição de algumas vagas dos profissionais demitidos ou que pedem demissão. Ocorre também um movimento de reconfiguração de alguns serviços, como as residências terapêuticas e o núcleo de internação, provocando uma redução ainda maior no número de profissionais contratados.

A inovação técnica e prática vai cedendo ao enquadramento jurídico e às portarias ministeriais. Todavia, essa convergência não é exclusiva de Campinas. Luzio e Yasui (2010) alertam que a tendência à regulamentação é um risco quando os processos de transformação vão perdendo as bases nos movimentos sociais e deslocam o foco de luta para o interior do aparelho estatal, como ocorreu com a Reforma Sanitária e tem ocorrido com a Reforma Psiquiátrica, pois a

ênfase nos processos de regulação como indutores da política do SUS transforma a potencialidade criativa e transformadora daqueles atores em uma servidão às normas e portarias. (LUZIO; YASUI, 2010, P. 22).

De tal forma que para Luzio e Yasui (2010, P. 23):

A sua institucionalização [da Reforma Psiquiátrica] transformou o Ministério da Saúde em seu principal ator e indutor chefe dos ritmos e dos rumos do processo. Parece não haver mais espaço para experiências que não sigam os parâmetros estabelecidos nas portarias, que, ironicamente, têm como inspiração as experiências do Caps e dos Naps, as quais trazem a marca da invenção e da criação que se construíram e obtiveram seu reconhecimento antes dessas regulações.

O Ministério da Saúde implanta, em 2013, novos registros de produção (Raas Registro das Ações Ambulatoriais de Saúde, BPA/I - Boletim de Produção Ambulatorial Individualizado, e BPA/C - Boletim de Produção Ambulatorial Consolidado) para qualificar as informações das ações desenvolvidas em saúde (BRASIL, 2013). Em Campinas, entretanto, tornaram-se instrumentos para o estabelecimento de metas para definir o repasse financeiro da Prefeitura para o SSCF, instaurando um clima de produtivismo entre os trabalhadores e gestores.

Tal situação denuncia a presença da lógica neoliberal na atual gestão da saúde do município, introduzindo mecanismos do mercado nas políticas públicas. Souza e Cunha (2013) apontam a existência de um avanço do modelo empresarial capitalista na nossa sociedade, de tal forma que se estabelece como natural que: "As famílias, os indivíduos, os bairros, as instituições públicas, ainda que educacionais ou de saúde, devem ser geridas 
como uma empresa" (SOUZA; CUNHA, 2013, P. 657). Tal perspectiva nega a saúde e a educação como direitos de todo o cidadão, conforme determina a Constituição Federal de 1988.

Em meio a toda essa transformação, houve, em Campinas, a contratação de novos profissionais, via concurso público, para ocupar os cargos na $\mathrm{AB}$ e para os futuros Centro de Atenção Psicossocial Infantil e Capsad (Centro de Atenção Psicossocial Álcool e Drogas). Certamente algo positivo dentro dessa conjuntura difícil por ser um investimento da Prefeitura nessa área. Por outro lado, demonstra um certo desinvestimento na parceria com o SSCF para novas empreitadas, mantendo-o reduzido às suas atuais ‘obrigações'.

A implantação dos serviços mais recentes na saúde mental como o Consultório na Rua (2012) e a Unidade de Acolhimento (2013), que eram aventados desde 2010, ocorreu seguindo as definições ministeriais e beneficiando-se do financiamento federal, no bojo das publicações de portarias, decretos e planos de 'enfrentamento do crack' entre 2009 e 2011. Pode-se dizer, sem querer retirar o mérito e a potencialidade desses serviços, que tais implantações tiveram um caráter mais reativo e oportunista do que de criação de alternativas para os problemas locais.

A situação tornou-se mais preocupante quando o governo municipal passou a atacar o modelo da Reforma Psiquiátrica, como ocorreu em abril de 2013, com o anúncio de implantação do Cratod (Centro de Referência de Álcool Tabaco e outras Drogas), em uma parceria com o governo do estado de São Paulo, criando, certamente, um fluxo propício e ágil para internações em comunidades terapêuticas e internações compulsórias. Tal iniciativa provocou protestos tanto no dia do seu anúncio como em manifestação organizada, no mês seguinte, diante do Paço Municipal.

Diante dessas mudanças, trabalhadores, gestores, usuários, familiares e acadêmicos promoveram eventos em defesa da saúde mental, tais como: Reafirmando o Contrário (2013), Resiste Campinas (2013 e 2014) e Mostra de Práticas de Saúde Mental (2015). Também foram redigidas cartas-manifesto direcionadas à Prefeitura, e ocorreram manifestações no Conselho Municipal de Saúde e em outros espaços públicos. Até mesmo o tradicional bloco de carnaval Unidos do Candinho $^{2}$ aderiu ao tom de protesto ao adotar a resistência como tema em 2014 (Arte e Resistência) e 2015 (Resistir com Arte).

A história e o acúmulo de práticas deixam marcas, mas os atuais sujeitos, no cotidiano, são desafiados a definir seus rumos e a lutar por eles. Em estudo recente, Oliveira (2014) identificou a relevância do apoio matricial na área de saúde mental em Campinas, mas que esse arranjo não tem encontrado suporte da gestão municipal, que investe pouco em espaços para reflexão da prática e da formação profissional e adota uma lógica produtivista e desvalorizadora dos espaços de encontro. A autora conclui que "realizar Apoio Matricial em Campinas atualmente significa empreender resistência política e que a cogestão ainda constitui uma proposta contra hegemônica" (OLIVEIRA, 2014, P. 147).

\section{O Fórum Colegiado de Saúde Mental: um dispositivo singular para construção do cuidado em rede}

No âmbito da saúde mental em Campinas, há os Fóruns Colegiados de Saúde Mental, espaços coletivos que existem nos cinco distritos de saúde da cidade, com composições e dinâmicas variadas, sem perder a dimensão colegiada, que tem como objetivo a "pactuação dos projetos de saúde mental na perspectiva da construção de redes de cuidado, seja a partir da discussão de casos ou não" (DORIGAN, 2013, P. 76). Segundo essa autora, trata-se de uma experiência singular de Campinas
$2 \mathrm{O}$ Bloco Unidos do

Candinho, organizado por usuários e trabalhadores do SSCF, desfila pelas ruas todos os anos desde 1993 
iniciada em 1998, antes de qualquer diretriz ministerial sobre rede de cuidado.

A denominação desses espaços coletivos como Fórum Colegiado de Saúde Mental foi dada por Dorigan (2013), ao considerar a variedade de temas abordados e a presença de participantes com diferentes inserções na rede de saúde. Nesses Fóruns, dada a diversidade de profissionais e serviços participantes, ocorre a transversalidade - conceito elaborado por Félix Guattari (LOURAU, 2014), que diz respeito à comunicação máxima que se efetua entre os diferentes níveis e sentidos no âmbito de um grupo e/ou de uma organização. Isso permite ao grupo escapar dos especialismos, trabalhar de forma mais interdisciplinar e lidar melhor com as diferenças.

Esses Fóruns, segundo Dorigan (2013), são potentes para a construção e avaliação das políticas públicas, além de serem acolhedores e importantes para a troca de experiências e produção de conhecimento entre os trabalhadores envolvidos, inclusive nos momentos mais críticos. Permite colocar em análise os arranjos organizacionais, como o apoio matricial, e sua operação-eficácia.

Devido à importância desses Fóruns na qualificação do cuidado em saúde mental, torna-se relevante investigar como a atual conjuntura permeia um deles, situado em uma região de alta vulnerabilidade social do município, e quais são os movimentos de resistência entre os seus participantes no desenvolvimento das suas práticas profissionais, tanto individuais como coletivas, para promover a articulação do cuidado em rede.

\section{Pesquisa de campo: método, sujeitos e estratégias}

Este artigo, na perspectiva da metodologia qualitativa, analisa a trajetória de um Fórum Colegiado de Saúde Mental durante um ano (junho de 2014 a junho de 2015), no qual o movimento de resistência dos profissionais participantes emergiu diante de uma proposta extraída em um coletivo de gestores. O primeiro autor acompanhou essa trajetória por meio de observação participante e registro em diário de pesquisa, que é uma ferramenta potente no âmbito da Análise Institucional (AI) de acordo com Pezzato e L'Abbate (2011). Foram também realizadas entrevistas semiestruturadas com intuito de complementar as informações com as concepções e opiniões de cada um dos integrantes do Fórum sobre determinados aspectos dessa construção do trabalho em rede. O projeto de pesquisa foi cadastrado na Plataforma Brasil (CAAE: 41629515.7.0000.5404) e aprovado pelo Comitê de Ética em Pesquisa da Universidade Estadual de Campinas em parecer emitido em 09/04/2015.

A análise do material utilizou conceitos da AI, como implicação e analisador. Conforme ressalta Lourau (2014), implicações de ordem afetiva, ideológica e profissional estão sempre presentes na relação dos sujeitos com as instituições e também nos vínculos estabelecidos com a sociedade mais ampla. Lourau (2014, P. 303) denomina analisador "àquilo que permite revelar a estrutura da organização, "provocá-la, forçá-la à falar"' (grifo nosso). Diante de um analisador, não é possível os sujeitos isentarem-se da tomada de posição, de modo que explicitam suas implicações com as instituições e os modos de agir.

Movimentos de resistência mantêm estreita proximidade com a noção de analisador - como pode-se verificar na discussão a seguir - justificando a importância de esmiuçar tais movimentos para analisar as contradições institucionais.

\section{A análise 'pelas' resistências nos movimentos institucionais}

René Lourau e Georges Lapassade, ao fundar 
a AI nos anos 1960/70 na França, propuseram um referencial teórico que articulou teoria e prática, buscando, seja sob a forma de investigação, seja de intervenção, abordar como os sujeitos formam e colaboram para provocar dialeticamente movimentos inovadores/instituintes nos grupos e organizações. (L'ABBATE, 2012).

Para Lourau (2004B, 2014), as instituições são dialeticamente constituídas por momentos instituídos e instituintes que resultam em processos de institucionalização. Como instituído, entende-se a ordem estabelecida, os valores, os modos de representação e de organização considerados normais, assim como os procedimentos habituais de previsão (econômica, social e política). Por outro lado, a contestação e a capacidade de inovação podem ser colocadas como sendo instituintes. Dessa forma, o instituído depende do instituinte para progredir, enquanto o instituinte depende do instituído para seguir com o projeto de transformação permanente.

Monceau (1997), na perspectiva da socioanálise - a AI em situação de intervenção -, elaborou um conceito de resistência operatório e dinâmico, com a finalidade de ampliar sua utilização no trabalho de formação que ele realizava com os professores franceses de ensino primário e secundário. Ainda que Monceau tenha trabalhado no campo educacional, e em outro contexto social, considerou-se a possibilidade de aplicar este conceito de resistência, visando compreender melhor a atuação dos profissionais no Fórum Colegiado de Saúde Mental que funciona em uma das regiões de Campinas.

Para melhor situar o problema da resistência, Monceau (1997) analisa três movimentos quanto à existência/permanência das instituições: institucionalização, autodissolução e transdução. O movimento de 'institucionalização' é descrito como o processo pelo qual a instituição se produz, o que nem sempre é puramente positivo, na medida em que cada instituição convive o tempo todo com sua negação. Assim, uma instituição pode, inclusive, produzir o fracasso de sua profecia inicial, ou seja, negar o objetivo que justificou sua fundação e até desaparecer. Decorre daí,

[...] o conceito de 'autodissolução' que corresponde a um modo de desaparecimento súbito das formas sociais, mas também do processo permanente de degradação que altera seu projeto [inicial], sua ideologia, seu funcionamento. (MONCEAU, 1997, P. 47, TRADUC̣ÃO NOSSA, GRIFO NOSSO).

Trata-se da negação sempre presente na dinâmica do trabalho. Os conceitos de institucionalização e autodissolução, portanto, não podem ser dissociados, pois o primeiro contém, de certo modo, o segundo, visto que qualquer instituição pode algum dia se dissolver. Os efeitos das suas contradições, traduzidas mais comumente como 'tensões' e/ou 'conflitos' mais ou menos 'latentes', podem crescer ou permanecer imperceptíveis por muito tempo e serem atualizados repentinamente.

A 'transdução', conceito atribuído a Gilbert Simondon, com inspiração nas leis da Física (SIMONDON, 1989 APUD COMBES, 1999), refere-se ao movimento de um acontecimento ou partícula que aos poucos provoca uma desorganização dos campos de força, em um determinado grupo ou instituição (GUILLIER; SAMSON, 1997-1998) ${ }^{3}$.

De acordo com Lourau (2004A, P. 213):

Simondon procura pensar a relação sujeito-objeto com base na 'transdução'. Como no espectro das cores, dois polos extremos e periféricos [o preto e o branco] são finais, limites. É a partir do centro (o verde-amarelo) que se sucedem as várias cores localizáveis e designáveis, fundando-se umas nas outras. Este movimento, resultado de potencializações e atualizações é a transdução.

\footnotetext{
3 "Conceito atribuído a Simondon, a transdução designa o movimento pelo qual um acontecimento uma partícula propaga pouco a pouco uma desorganização dos campos de forças, criadora de formas novas" (GUILLIER; SAMSON, 1997-8, P. 29, TRADUC̣ÃO NOSSA).
} 
Monceau (1997) destaca a relevância de atentar aos entremeios das relações institucionais nesses três movimentos e aos anúncios pouco perceptíveis, que se pode chamar de latentes, por eles revelarem os rumos tomados por uma determinada instituição, inclusive aqueles em direção à sua autodissolução.

A partir de uma investigação na literatura científica em diversas áreas do conhecimento, Monceau (1997) afirma ter sido conduzido a uma definição da resistência como força social em oposição a outra chamada poder, sendo que o equilíbrio entre elas tende a favorecer o segundo. Identifica que os usos e significados da palavra resistência têm dois polos, independentemente da disciplina, sendo que o primeiro faz referência à luta contra a opressão e tem caráter revolucionário, ao passo que o segundo é mais conservador e tende à preservação do que já existe.

Entretanto, o autor procura construir um conceito operatório de resistência, que possa contribuir para as práticas socioanalíticas e para as pesquisas em AI. Propõe a análise resistencial, que seria a análise 'pelas' resistências, não a tradicional análise 'das' resistências. A proposta é considerar as questões sociopolíticas envolvidas ao invés de concentrar-se apenas em um elemento deturpado ou desviante do funcionamento normalmente esperado. Ou seja, tomar a resistência como analisador das contradições institucionais.

Com a pretensão de formular um conceito que fosse dinâmico e operativo, Monceau (1997) o apresenta composto em três instâncias que constituem os momentos dialéticos: ofensivo, defensivo e integrativo. Esclarece que eles se contradizem entre si, pois: 1) o 'defensivo' tem origem na obra freudiana e corresponde ao momento conservador; 2) o 'ofensivo' corresponde ao polo mais revolucionário; 3) o 'integrativo’ é uma alternativa a essa oposição, sem ser capaz de ser situado entre eles.

Esse autor ilustra (figura 1) a relação entre os três, com a ressalva de que a representação não deve ser tomada como estática, mas sim em movimento, e sua análise deve ter um caráter dinâmico. Afirma que a força social designada de resistência implica necessariamente, na sua atualização, para a constituição de um poder, e que existem 'zonas de interferências', nas regiões de encontro entre os momentos. 
Figura 1. A representação dialética dos três movimentos do conceito de resistência

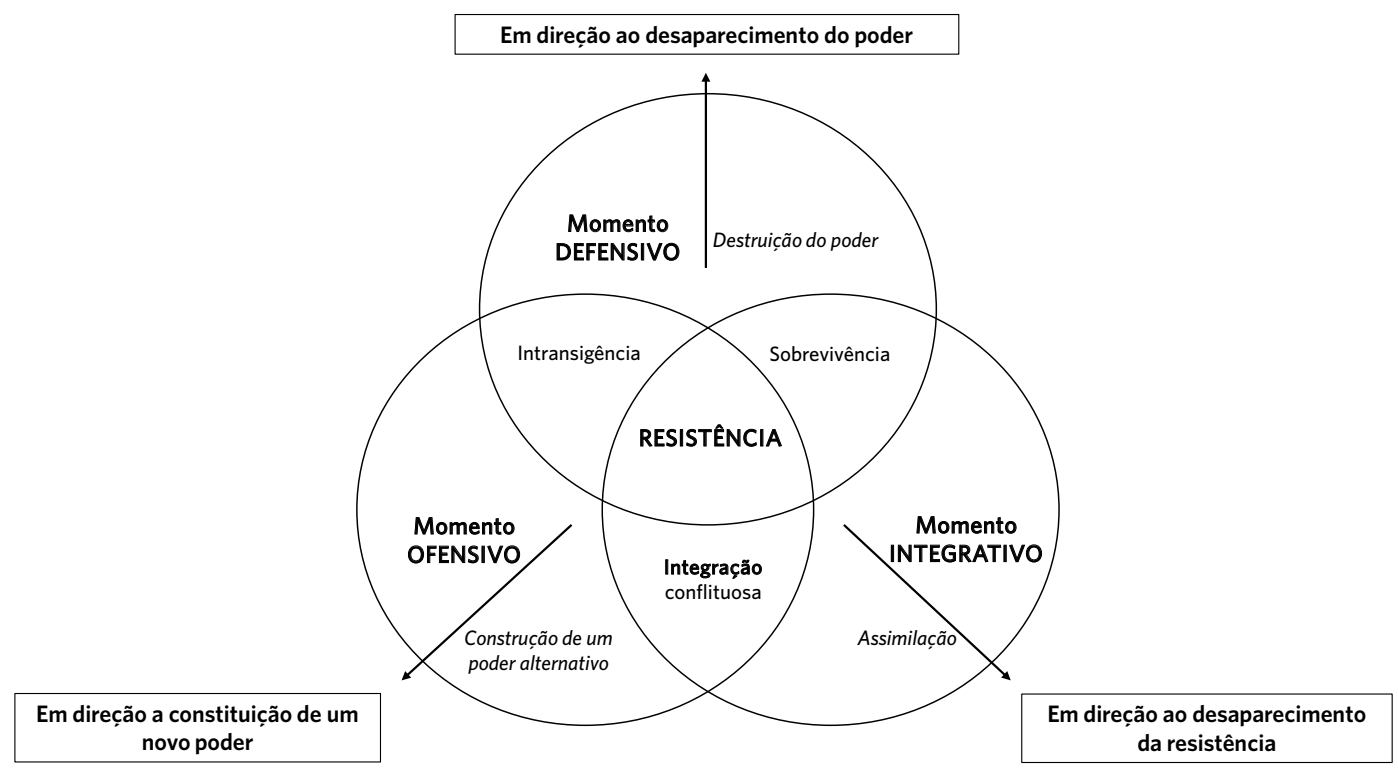

Fonte: Monceau (1997, TRADUÇÃO NOSSA)

O 'momento defensivo', para o autor, é quando a autodissolução domina a institucionalização, então esse movimento identifica-se à resistência e tende à destruição do poder. Nota-se uma parte da intransigência que corresponde à autopreservação sem qualquer compromisso com o poder; e outra parte de sobrevivência, na qual há formação de defesa da integridade física, mental e coletiva em uma situação vivida como extrema.

No 'momento ofensivo', a busca é pela constituição de um novo poder contrainstitucional, dentro da forma social ou fora dela. Dentro desse momento, observa-se a intransigência como constituição de um novo poder sem qualquer compromisso com o poder dominante, ou seja, cria-se uma dissidência. Já a integração conflituosa remete ao estabelecimento de um novo poder na contradependência do poder, como no caso da resistência que adota um modo institucional da ação (por exemplo, o sindicalismo).

O 'momento integrativo' mantém uma relação com a negatividade da autodissolução, na qual a resistência tende à assimilação para evitar o desmanche. A resistência é reprimida e permanece latente, acumulando tensões e conflitos sem serem abordados no processo institucional. A sobrevivência também compõe esse movimento, envolvendo falsidade, dissimulação, absenteísmo, retirada, perda de interesse e qualquer outra estratégia para permanecer integrado e protegido. Outra parte desse movimento é a integração conflituosa, que ocorre quando, por exemplo, um grupo minoritário é integrado ao grande grupo por meio de brincadeiras grosseiras.

Monceau (1997) explica que os três eixos centrífugos sugerem três formas de potencialização: 1) em direção ao desaparecimento do poder, destruindo-o; 2) em direção 
${ }^{4}$ Campinas conta com cinco Distritos de Saúde. ao desaparecimento da resistência pela assimilação ao poder; 3) em direção à construção de um novo poder que seja alternativo. Da mesma forma, considera a potencialização a partir das 'zonas de interferência': 1) pela intransigência, desviando das normas que sustentam o poder pela recusa; 2) a partir da sobrevivência pela morte física, desestruturação psíquica ou despersonalização; 3) a partir da integração conflituosa com o cruzamento das fronteiras, a fuga ou a deserção.

A resistência, segundo Monceau (1997), só tem sentido no contexto institucional quando ela anuncia algo e contribui para analisar a instituição. Em outro texto, Monceau (2008) analisou intervenções que realizou com professores de diversas organizações francesas de ensino primário e secundário em um período de 14 anos (1992 a 2006). Nas intervenções, com caráter de formação e produção participativa de novos conhecimentos, havia a proposta dos participantes analisarem as suas práticas, considerando suas implicações pessoais e em relação ao contexto institucional, como forma de evitar que a reflexão se encerrasse em uma noção de que a prática profissional fosse uma mera produção individual. O autor considera que, ao se colocar as instituições em questão, abre-se a possibilidade de tratar as ações de resistência de outra maneira. Para Monceau $(1997,2008)$, a resistência deve ser tratada como analisador das instituições.

$\mathrm{O}$ analisador, que é um dos principais conceitos da AI, foi inicialmente utilizado por químicos e físicos como um elemento natural ou construído, capaz de decompor a realidade material em seus elementos componentes para experimentações e análises. Isto é, trata-se de um elemento capaz de produzir revelação. Na prática da AI, os analisadores têm uma primazia sobre o analista, de tal forma que o trabalho do analista é justamente localizá-los no grupo para provocar a análise (LAPASSADE, 1979).

\section{Movimento de resistência pela manutenção de um dispositivo de articulação de rede}

Em uma das regiões mais vulneráveis e periféricas da cidade de Campinas, três Centros de Saúde (CS) sofriam com alta rotatividade de profissionais de saúde mental e chegaram a passar períodos sem nenhum, refletindo as dificuldades de convênio entre Prefeitura e SSCF, conforme mencionado no início deste texto. Em 2013, havia uma psicóloga e uma terapeuta ocupacional atuando na região, com pouca articulação com os demais serviços da rede e sem conseguir aproximar as equipes da Atenção Básica com os Caps. Nem mesmo a estratégia de visitas domiciliares conjuntas do Centro de Atenção Psicossocial com um dos CS promovia ganhos para o compartilhamento do cuidado, pois contava apenas com a participação de agentes comunitários de saúde, sem conseguir angariar novas parcerias. $\mathrm{O}$ 'assento' formal em um Fórum Colegiado de Saúde Mental mais ampliado que supostamente abrangia esse território era apenas uma formalidade, pois não tinha participação de nenhum representante da região.

Em meio à crise na relação entre Prefeitura e SSCF (em junho de 2013), em uma reunião no Distrito de Saúde 4 que contou com a presença de profissionais da $\mathrm{AB}$ e dos Caps, bem como gestores locais e distritais, foi criado o primeiro Fórum Colegiado de Saúde Mental nessa região com a perspectiva dos Caps se aproximarem mais desse território e ser um dispositivo para disparar ações de compartilhamento de cuidado a partir da discussão de casos. Na sua composição, foram incluídos profissionais de saúde mental e das equipes de referência da $\mathrm{AB}$, profissionais do Centro de Atenção Psicossocial e do Capsad, além da abertura para participação de membros da gestão local e distrital.

Ao longo de um ano, em um processo de 
institucionalização, os encontros do Fórum passaram a ser quinzenais, e foi incluída uma interconsulta mensal com a psiquiatra do Centro de Atenção Psicossocial deslocando-se aos CS. De modo que, pela necessidade avaliada pelos seus membros, passaram a existir três encontros mensais.

Entretanto, em maio de 2014, duas profissionais do Centro de Atenção Psicossocial foram convidadas a participar de uma reunião com os gestores locais e distritais para avaliar como estava o cuidado em rede na área de saúde mental. A gestora de um CS avaliou que o Fórum estava funcionando mal, o que surpreendeu as duas profissionais já que nenhuma queixa havia sido levada para o Fórum até então e elas avaliavam bem o espaço. Entretanto, essa má avaliação determinou a elaboração de uma proposta, nesse espaço de gestores, de diminuição para uma reunião mensal e a manutenção da interconsulta.

Quando as profissionais do Centro de Atenção Psicossocial repassaram a proposta no encontro seguinte do Fórum, houve uma surpresa geral entre os participantes que discordaram tanto da avaliação negativa quanto da ideia de diminuição dos encontros. O coletivo passou a justificar a necessidade de preservação do atual formato. Um dos médicos da $\mathrm{AB}$ enfatizou que só mantinha os atendimentos de saúde mental - pelos seus cálculos, cerca de $60 \%$ dos seus atendimentos -, pois contava com essa retaguarda técnica. Um psicólogo do Capsad argumentou que esse Fórum estava funcionando dentro da proposta do matriciamento (indicação de políticas de saúde), mantendo discussões de alta qualidade e disparando outras ações (capacitações, visitas e consultas compartilhadas etc.). Outros profissionais dos CS valorizaram o espaço para o desenvolvimento de suas ações de saúde mental no cotidiano, reconhecendo a importância desse espaço para lidar com os casos complexos, que causam impacto afetivo e reflexão sobre os valores morais.
Para uma das profissionais do Centro de Atenção Psicossocial que ficou na delicada intermediação entre o coletivo de gestores e o Fórum, essa reunião teve grande importância:

Eu acho que esse dia foi muito importante, porque a gente se constitui como grupo de matriciamento. Antes não era tanto assim. A gente não tinha uma afinidade, uma cumplicidade. Nesse dia, a gente conseguiu se fortalecer muito, porque tratamos das nossas dificuldades.

De pronto, o Fórum rejeitou a proposta de diminuição dos encontros e passou a formular estratégias para justificar a sua relevância ante os gestores. O fato dos profissionais terem resistido a essa mudança de funcionamento do Fórum promoveu maior aproximação entre os membros mais ativos e um movimento de qualificar ainda mais o espaço, especialmente na melhor organização dos encontros e preparação dos casos para discussão.

Tal movimento de defesa do cuidado em rede favoreceu a entrada de novos profissionais de saúde mental em uma lógica de trabalho em equipe, como conta um dos psicólogos da AB:

Quando eu entrei, estava havendo um movimento dentro do grupo de matriciamento de afirmação dessa prática, porque estava havendo alguns boicotes. Eu via alguns profissionais se posicionarem e argumentarem em favor dessa rede, e eu estava com a angústia de um profissional que tinha uma experiência de trabalho em consultório com atendimentos em série. Comecei a assimilar um pouco do discurso desses profissionais, porque ele realmente fazia sentido na minha prática, me aliviava muito.

A gestão não insistiu na proposta de diminuição no próprio Fórum, mas houve algumas cobranças dirigidas aos profissionais de saúde mental e aos médicos alocados na $\mathrm{AB}$, no sentido de aumentar o número de 
atendimentos individuais em detrimento do trabalho com as equipes e outros serviços, exigindo que o Fórum se posicionasse diante dos gestores. A estratégia elaborada foi a de realizar uma supervisão clínico-institucional com a presença de gestores locais e distritais, tendo a intenção de exibir o nível de complexidade dos casos e consequentemente a necessidade de preservação da frequência dos encontros. Essa supervisão, além da discussão do caso em si, possibilitou a análise das convergências e divergências entre profissionais e gestores quanto ao formato da articulação em rede nessa região.

Após a supervisão, ainda permaneceram alguns resquícios do mal-estar entre os profissionais e os gestores, mas o Fórum fortaleceu a sua sustentação, e a apoiadora de saúde mental do distrito passou a defender com mais ênfase o Fórum perante os demais gestores.

\section{Resistência como analisador da gestão e da saúde mental em Campinas}

Conforme a descrição de Monceau (1997) sobre os movimentos de resistência, pode-se dizer que o Fórum adotou uma posição na intersecção entre o momento defensivo e ofensivo, denominado pelo autor de 'intransigência'. Nessa situação, os membros do Fórum, para defender o formato do espaço, adotaram movimentos ofensivos, não se submetendo às decisões tomadas em uma reunião de gestores e colocando em análise os motivos da proposta e as razões para a sua recusa. A intransigência, nesse caso, teve espaço para ser elaborada entre os seus membros, não sendo fruto de um comportamento insensato ou de comodismo.

Percebe-se, retomando o conceito de transdução, que houve atualização e potencialização de caráter transdutivo da resistência pela intransigência nesse Fórum, pois, segundo Monceau (1997), isso ocorre quando, pela recusa, há um desvio das normas que sustentam o poder. No movimento de resistência desse Fórum, houve uma recusa em seguir a 'hierarquia da gestão', ao não tomar as palavras de uma gestora como verdadeira e uma ordem a ser seguida, e assumir a dianteira na gestão do Fórum; e também houve uma recusa em entrar na 'ordem do enquadre', mantendo um espaço coletivo de saúde mental com uma frequência que possibilita criações.

Sobre a reação perante a 'hierarquia da gestão', nota-se que, em um primeiro momento, a avaliação do Fórum é feita fora dele, com a fala de uma gestora sendo tomada como palavra definitiva, orientadora de ações e motor para mudanças decididas em um espaço de gestores para depois ser levada 'pronta' para os profissionais em um encontro do Fórum. Ou seja, tal avaliação sobrepôs 'naturalmente' à dos demais profissionais. Tal pressuposição da hierarquia não é algo apenas de gestores, pois os próprios profissionais que estavam presentes na tal reunião no Distrito assumiram a tarefa de repassar a má avaliação e a proposta de redução de encontros. Nem mesmo a discordância com relação à decisão promoveu uma recusa em levar adiante a decisão naquele momento. $\mathrm{O}$ movimento de resistência foi potencializado no próprio Fórum, quando a análise foi feita pelo coletivo.

Tal resistência, como um analisador, oportunizou a possibilidade de reposicionamentos dos envolvidos (profissionais e gestores). $\mathrm{O}$ evento teve como efeito a tomada de gestão do Fórum pelos próprios participantes, que passaram a defender mais o espaço e a organizar o seu funcionamento. A gestão não confrontou esse movimento do Fórum, respeitando as suas decisões, que eram fundamentadas, e demonstrando que a experiência mais colegiada e democrática na gestão da saúde campineira deixou algumas marcas. Essa gestão mais autônoma do Fórum provocou nos seus integrantes 
movimentos para qualificação da sua finalidade de compartilhamento do cuidado, inclusive oportunizando a análise das práticas profissionais, com abertura para revisões e novas construções entre seus membros e gestores. Dentro de um processo de deslocamento da prática profissional frequentemente proporcionado pelos desafios cotidianos e pelas análises empreendidas nesse Fórum, um dos membros argumenta que:

O Fórum deve funcionar e ser priorizado, porque é uma espécie de formação a longo prazo do profissional. Sem falar nos ganhos pessoais. Ele aumenta a autoestima profissional e a autoconfiança. Eu acho que o profissional munido desse sentimento, rende bem melhor.

Além da gestão, esse movimento de resistência permite analisar a força do enquadre diante da inovação na atual conjuntura campineira, pois um Fórum que evidentemente estava, a partir da identificação das necessidades locais, conseguindo desenvolver diversas ações dentro das proposições de cuidado em rede, foi atravessado por uma indicação de que estava 'fazendo demais'. $\mathrm{O}$ que leva a interpretar que o enquadre das produções na área de saúde mental (parâmetros definidos em políticas e portarias) indica a necessidade de haver 'ações de articulação em rede', mas esse não pode ser muito: 'deve apenas existir'. O que é um grande equívoco, pois para esse Fórum, por exemplo, a frequência maior de encontros é o que permite a construção do trabalho em rede, segundo os entrevistados porque há muitos usuários que demandam a construção de estratégias de compartilhamento, visto que os casos apresentam alto nível de complexidade e há barreiras de acesso e dificuldades de seguimento do cuidado em outros serviços devido à alta vulnerabilidade dessa população e distância dos demais equipamentos públicos. Uma profissional do Centro de Atenção Psicossocial, que participa do Fórum, enfatiza a importância dessa frequência:
Alguns podem achar que é muito tempo. Mas eu acho que isso é necessário para lógica de trabaIho em rede, as construções conjuntas e o trabaIho junto com a Atenção Básica.

A resistência empreendida por esse coletivo também é um analisador da desvalorização do trabalho em rede na saúde mental na atual conjuntura, considerando que se trata de um coletivo que só conseguiu se institucionalizar recentemente e sofreu uma ameaça de dissolução após menos de um ano do seu funcionamento. Entretanto, além de defender a sua preservação, o coletivo integrou profissionais de CS da Prefeitura e Caps do SSCF - em um movimento oposto ao que ocorre entre as entidades no âmbito municipal -, evidenciando a forte disposição-investimento-implicação desses diversos profissionais com o trabalho em rede, com a qualidade da saúde mental e com os princípios do Sistema Único de Saúde (SUS), mesmo diante das ameaças de desmonte e fragmentação.

\section{Considerações finais}

A resistência, ao expor movimentos de contradição, pode alimentar diversas análises. Pela dialética, as contradições são sempre fontes para entender os movimentos institucionais. As resistências podem ser movimentos de comodismo ou retaliação, mas podem ser movimentos de sustentação de boas práticas em conjunturas de precarização. Para que as resistências possam sair da paralisia e adquirir movimento, elas devem ser analisadas em coletivo incluindo às dimensões institucionais que as permeiam. A recusa à proposta, por exemplo, deve servir de elemento de análise para a situação.

Há um processo em que a regulamentação e o enquadre têm sobressaído na saúde mental em Campinas, o que reduz horizontes mais criativos e singulares. As saídas para os frequentes desafios, dessa forma, tornam-se 
mais estreitas, espremendo as práticas profissionais e de gestão. Espaços coletivos, como o Fórum Colegiado de Saúde Mental, parecem potentes para reanimar a criatividade necessária para o cuidado singular e qualificado em saúde mental. Certamente, configuram-se em espaços de resistência.

Ou seja, muitos profissionais de saúde mental de Campinas, diante de uma conjuntura adversa que coloca os espaços coletivos e de articulação entre serviços em risco de dissolução, ainda resistem e trabalham para

\section{Referências}

AMARANTE, P. Loucos pela vida: a trajetória da Reforma Psiquiátrica brasileira. Rio de Janeiro: Fiocruz, 1995.

BRASIL. Ministério da Saúde. Sobre os novos procedimentos de CAPS. Nota técnica. Brasília, DF: Ministério da Saúde, 2013. Disponível em: <http://u.saude.gov.br/images/pdf/2015/janeiro/29/ Documento-Sobre-Procedimentos-de-CAPS-RAASPSI.pdf $>$. Acesso em: 21 nov. 2015.

CAMPOS, F. C. B. O modelo da Reforma Psiquiátrica Brasileira e as modelagens de São Paulo, Campinas e Santos. 2000. 178f. Tese (Doutorado em Saúde Coletiva) - Faculdade de Ciências Médicas, Universidade de Campinas, Campinas, 2000.

COMBES, M. Simondon Individu et Collectivité: pour une philosophie du transindividuel. Paris: PUF, 1999.

CUNHA, G. T.; CAMPOS, G. W. S. Apoio matricial e Atenção Primária em Saúde. Saude Soc., São Paulo, v. implementar o cuidado em rede. $\mathrm{O}$ acúmulo dessas práticas coletivas poderá, sem dúvida, produzir avanços mais permanentes no atendimento à saúde mental, até porque o Fórum deve continuar a funcionar pelo posicionamento declarado dos seus membros.

Além disso, espera-se que esta experiência possa inspirar análises semelhantes em outros locais, que, dada a situação atual do SUS em todo o Brasil, certamente podem estar vivenciando situações semelhantes à do município de Campinas.
20, n. 4, p. 961-970, dez. 2011.

DORIGAN, J. H. Fóruns colegiados: espaços transversalizados na construção da atenção em Saúde Mental de Campinas. 2013. Dissertação (Mestrado em Saúde Coletiva) - Faculdade de Ciências Médicas, Universidade de Campinas, Campinas, 2013.

FIGUEIREDO, M. D.; SANTOS, D. V. D. A rede de saúde do município de Campinas (SP): peculiaridades e inovações. In: ONOCKO CAMPOS, R. T. et al. (Org.). Pesquisa avaliativa em Saúde Mental: desenho participativo e efeitos da narratividade. São Paulo: Hucitec, 2008.

GUILLIER, D.; SAMSON, D. Implication: des discours d'hier aux pratiques d'aujourd'hui. Les cahiers de l'implication. Revue d'analyse institutionnelle. n. 1, p. 17-29, 1997-1998.

L’ABBATE, S. Análise Institucional e Intervenção: breve referência à gênese social e histórica de uma 
articulação e sua aplicação na Saúde Coletiva.

Mnemosine, Rio de Janeiro, v. 8, n. 1, p. 194-210, 2012.

Direito à saúde: discursos e práticas na

construção do SUS. São Paulo: Hucitec, 2010.

LAPASSADE, G. El analizador y el analista. Barcelona: GEDISA, 1979.

LOURAU, R. A Análise Institucional. 3. ed. Petrópolis, RJ: Vozes, 2014.

Implicação-transdução. In: ALTOÉ, S. (Org.). René Lourau: analista institucional em tempo integral. São Paulo: Hucitec, 2004a. p. 212-223.

O instituinte contra o instituído. In: ALTOÉ, S (Org.). René Lourau: analista institucional em tempo integral. São Paulo: Hucitec, 2004b. p. 47-65.

LUZIO, C. A.; YASUI, S. Além das portarias: desafios da política de saúde mental. Psicologia em Estudo, Maringá, v. 15, n. 1, p. 17-26, jan./mar. 2010.

MONCEAU, G. Como as instituições permeiam as práticas profissionais: socioclínica institucional e formação de professores. In: PIMENTA, S. G.; FRANCO, M. A. S. (Org.). Pesquisa em educação: possibilidades investigativas/formativas da pesquisaação. v. 1. São Paulo: Loyola, 2008.

Le concept de résistance en education. Pratiques de formation: analyses, n. 33, p. 47-57, 1997.

OLIVEIRA, M. M. Apoio matricial na Atenção Básica de Campinas: formação e prática. 2014. Dissertação (Mestrado em Saúde Coletiva) - Faculdade de Ciências Médicas, Universidade de Campinas, Campinas, 2014.

PEZZATO, L. M.; L’ABBATE, S. Os usos de diários como ferramenta de intervenção da análise institucional: potencializando reflexões no cotidiano. Physis, Rio de Janeiro, v. 21, n. 4, p. 1297-1314, 2011.

SOUZA, T. P.; CUNHA, G. T. A gestão por meio da avaliação individualizante e competitiva como elemento comum nas políticas públicas e gerenciais contemporâneas: uma contribuição crítica a partir de Michel Foucault. Saúde em Debate, Rio de Janeiro, v. 37, n. 99, p. 655-663, out./dez. 2013.

Recebido para publicação em dezembro de 2015

Versão final em maio de 2016

Conflito de interesses: inexistente

Suporte financeiro: não houve 